\title{
GAMBARAN KARAKTERISTIK BALITA DENGAN MALARIA DI PUSKESMAS SENTANI KABUPATEN JAYAPURA
}

\author{
Asrisal ${ }^{1}$, Juliawati ${ }^{2}$, Lisma Natalia Br Sembiring ${ }^{1}$ \\ ${ }^{1}$ Prodi Keperawatan Stikes Jayapura, ${ }^{2}$ Universitas Cenderawasih \\ Email: prodikep.stikesjypr@yahoo.com
}

\begin{abstract}
ABSTRAK
Malaria adalah penyakit yang mengancam nyawa yang disebabkan oleh parasit yang ditularkan kepada manusia melalui gigitan nyamuk Anopheles betina. Anak balita merupakan salah satu kelompok yang rentan terinfeksi malaria. Diperkirakan sekitar 438.000 angka kematian akibat malaria diseluruh dunia pada tahun 2015, 69\% terjadi pada balita. Tujuan penelitian untuk menggambarkan karakteristik balita dengan malaria di Puskesmas Sentani Kabupaten Jayapura. Jenis penelitian yaitu penelitian deskriptif kuantitatif. Penelitian dilakukan di Puskesmas Sentani Kabupaten Jayapura pada bulan Agustus 2016. Populasi dalam penelitian adalah orang tua dari balita dengan malaria yang berobat di Puskesmas Sentani Kabupaten Jayapura dengan jumlah sampel sebanyak 59 orang. Data diperoleh menggunakan kuesioner dan dianalisa secara univariat. Hasil penelitian menunjukkan Sebagian besar umur balita yang terkena malaria adalah yang berumur 2 tahun $(28,8 \%)$, jenis kelamin laki-laki $(52,5 \%)$, jenis malaria Tropika (74,6 \%), keluhan awal dengan kriteria berat sebanyak 41 responden $(69,5 \%)$ dan lingkungan tempat tinggal tidak berisiko tinggi malaria sebanyak 35 responden $(59,3 \%)$.
\end{abstract}

Kata kunci : Malaria, Karakteristik, Balita. 


\begin{abstract}
Malaria is a life threatening disease caused by parasites that are transmitted to humans through the bite of a female Anopheles mosquito. The under five years is one of the most vulnerable groups exposed to malaria. It is estimated that around 438,000 numbers of malaria deaths worldwide in 2015, 69\% occurred in infants. The research objective to describe the characteristics of children under five with malaria at the Sentani public health center Jayapura regency. This type of research is quantitative descriptive study. The study was conducted in Sentani public health center Jayapura regency in August 2016. The population in the study are the parents of a under five years with malaria seek treatment at the Sentani public health center Jayapura Regency with a total sample of 59 people. The data were obtained using a questionnaire and analyzed by univariate. The results showed age Most under five years are exposed to malaria is a 2-year $(28.8 \%)$, male gender $(52.5 \%)$, the type of malaria Tropical (74.6\%), the initial complaint with the criteria as much weight 41 respondents $(69.5 \%)$ and living environment are not at high risk of malaria by 35 respondents $(59.3 \%)$.
\end{abstract}

Keyword : Malaria, Characteristic, Under five years. 


\section{LATAR BELAKANG}

Malaria adalah penyakit yang mengancam nyawa yang disebabkan oleh parasit yang ditularkan kepada manusia melalui gigitan nyamuk Anopheles betina. Pada tahun 2015, terdapat 95 negara yang telah mengalami penyebaran malaria.

Sekitar 3,2 milyar jiwa atau hampir separuh dari populasi dunia beresiko terkena malaria. Anak balita merupakan salah satu kelompok yang rentan terinfeksi malaria. Diperkirakan sekitar 438.000 angka kematian akibat malaria diseluruh dunia pada tahun 2015, 69\% terjadi pada anak usia dibawah 5 tahun (WHO, 2016).

Malaria masih merupakan
masalah kesehatan masyarakat
ditingkat global, demikian pula di
Indonesia. Adapun kasus positif malaria pada tahun 2015 yaitu sebanyak 209.413 kasus (Kemenkes RI, 2016). Berdasarkan laporan penemuan dan pengobatan malaria provinsi Papua tahun 2015, didapatkan data positif malaria pada usia 1-4 tahun yaitu sebanyak 27.983 kasus. Bahkan masih ada beberapa kabupaten di provinsi Papua yang laporannya belum masuk ke Dinas Kesehatan Provinsi Papua (Dinkes Papua, 2015).

Data Dinas kesehatan kabupaten Jayapura tentang laporan penemuan dan pengobatan malaria kabupaten Jayapura dari bulan Januari sampai Desember 2015 terdapat 2.600 kasus malaria pada usia 1-4 tahun (Dinkes Kabupaten Jayapura, 2015). Adapun laporan bulanan penemuan dan pengobatan malaria di Puskesmas Sentani bulan Januari-April 2016, tercatat sebanyak 265 kasus malaria pada anak usia 1-4 tahun. Wilayah kerja puskesmas Sentani ada 10 kampung. Dari kesepuluh kampung tersebut, hanya satu kampung yang tidak terdapat balita yang berobat di Puskesmas Sentani karena malaria. Adapun distribusi pengobatan malaria pada balita berdasarkan kampung sebagai berikut: Sentani: 136 orang, Hinekombe: 90 orang, Dobonsolo: 17 orang, Sereh: 38 orang, Yobeh: 11 orang, Ifale: 21 orang, Yoboi: 24 orang, Ifar besar: 1 orang, Yahim: 20 orang dan Hobong tidak ada. Dari data tersebut pengobatan terbanyak berada pada kampung Sentani dan 
terendah yaitu Hobong (tidak ada). Adapun distribusi jenis malaria secara umum yaitu: Malaria Tropika: 1.308 kasus, Malaria Tertiana: 665, Malaria Mix: 26, Malaria Quartana: 11 dan Malaria Ovale tidak ada. Dari data tersebut dapat disimpulkan bahwa jenis malaria terbanyak adalah Malaria Tropika dan terendah yaitu Malaria Ovale (tidak ada). Perbandingan penderita malaria pada balita berdasarkan jenis kelamin tidak terlalu signifikan tapi laki-laki lebih banyak daripada perempuan, yaitu laki-laki sebanyak 195 kasus dan perempuan 170 kasus (Puskesmas Sentani, 2015).

Anak merupakan generasi penerus bangsa, apabila anak sehat maka tumbuh kembang anak akan baik . Namun jika anak sering terkena penyakit seperti malaria maka tumbuh kembang anak akan terganggu, untuk itu pentingnya perhatian yang harus diberikan oleh orang tua dalam memperhatikan perkembangan anak sehari-hari agar menghindarkan atau meminimalisir anak dari berbagai penyakit khususnya penyakit malaria.
Penelitian ini mengambil lokasi di Puskesmas Sentani karena ingin mengetahui gambaran karakteristik balita dengan penyakit malaria. Adapun yang mendasari peneliti tertarik meneliti tentang malaria pada balita di Puskesmas Sentani karena semakin meningkatnya jumlah balita yang datang berobat di Puskesmas Sentani khususnya malaria (tercatat 265 kasus balita dari Januari-April 2016).

Menurut karakteristik umur, point prevalence paling tinggi adalah pada umur 5-9 tahun (0,9\%), kemudian pada kelompok umur 1 -4 tahun $(0,8 \%)$ dan paling rendah pada umur $<1$ tahun $(0,3 \%)$. Sedangkan menurut period prevalence, prevalens paling tinggi adalah pada kelompok umur $>15$ tahun $(10,8 \%)$, nomor dua paling tinggi pada kelompok umur 1-4 tahun $(10,7 \%)$ dan paling rendah tetap pada umur $<1$ tahun $(8,2 \%)$. Dari data di atas tampak kecenderungan kelompok yang berisiko tinggi terkena malaria bergeser dari usia >15 tahun ke usia 1-4 tahun (Kemenkes RI, 2011). Adapun penelitian lain pada balita yang terkena malaria yaitu: kategori 
umur 12-23 bulan (100\%) dan 2-4 tahun tidak ada (Gusra dkk, 2016). 12-23 bulan (50\%) dan 2-4 tahun (50\%) (Dwithania dkk, 2012).

Menurut karakteristik jenis kelamin terhadap anak yang terkena malaria, pada beberapa penelitian yaitu: penelitian yang dilakukan di Kabupaten Kulonprogo Yogyakarta, didapatkan hasil laki-laki: 87 (55,7\%) dan perempuan: $69(44,3 \%)$ (Solikhah, 2013). Penelitian yang dilakukan di Kabupaten Kupang, didapatkan hasil laki-laki: 122 (65,7\%) dan perempuan: $63(34,3 \%)$ (Ngambut dan Sila, 2013). Penelitian di Kabupaten Melawi Kalimantan Barat, didapatkan hasil laki-laki: $60,3 \%$ dan perempuan 39,7 \% (Ristadeli, 2013).

Distribusi jenis malaria yang dilakukan oleh beberapa peneliti sebagai berikut: penelitian di kota Sawahlunto didapatkan hasil: tertiana $(76,92 \%)$, tropika $(15,38 \%)$ dan quartana (7,69\%) (Dwithania dkk, 2012). Penelitian di Kabupaten Pesisir Selatan didapatkan hasil: tropika $(91,67 \%)$ dan Tertiana $(8,33 \%)$ (Gusra dkk, 2013).
Berdasarkan wawancara singkat peneliti dengan seorang perawat di Puskesmas Sentani, didapatkan informasi mengenai keluhan yang umum dirasakan oleh pasien dengan malaria di Puskesmas Sentani yaitu: demam, menggigil, sakit kepala, mual muntah dan nafsu makan berkurang.

Beberapa hasil penelitian mengenai lingkungan tempat tinggal yang menjadi faktor penyebab malaria yaitu: tidak memasang kawat kasa pada semua ventilasi, keberadaan genangan air dekat rumah, kebiasaan tidak memakai kelambu saat tidur pada malam hari (Kurniawan, 2008). Dinding rumah yang terbuat dari kayu/papan (Babba, 2007). Keberadaan kolam, keberadaan semak di sekitar rumah, keberadaan genangan di sekitar rumah, (Ristadeli dkk, 2013). Keberadaan genangan air, keberadaan semak-semak, jenis dinding rumah dan tidak menggunakan obat anti nyamuk (Wahyuningtyas, 2011).

Berdasarkan uraian di atas, maka peneliti tertarik untuk melakukan penelitian mengenai 
gambaran karakteristik balita dengan malaria di Puskesmas Sentani.

\section{METODE PENELITIAN}

Desain penelitian ini menggunakan jenis penelitian deskriptif kuantitatif. Penelitian deskriptif adalah suatu metode penelitan yang dilakukan dengan tujuan utama untuk membuat gambaran tentang suatu keadaan secara objektif (Setiadi, 2013). Sedangkan metode penelitian kuantitatif dapat diartikan sebagai metode penelitian yang berlandaskan pada filsafat positivisme digunakan untuk meneliti pada populasi atau sampel tertentu, teknik pengambilan sampel pada umumya dilakukan secara random (Sugiono, 2011).

Penelitian ini dilakukan di Puskesmas Sentani, pelaksanaan penelitian ini telah dilakukan pada tanggal 05 Agustus s/d 13 Agustus 2016.

Populasi merupakan wilayah generalisasi yang terdiri atas objek/subjek yang mempunyai kualitas dan karakteristik tertentu yang ditetapkan oleh peneliti untuk dipelajari dan kemudian ditarik kesimpulannya. Jadi populasi bukan hanya orang, tetapi juga objek dan benda-benda alam yang lain. Populasi juga bukan sekedar jumlah yang ada pada objek/subjek yang dipelajari, akan tetapi meliputi seluruh karakteristik/sifat yang dimiliki oleh objek/subjek itu (Setiadi, 2013). Populasi dalam penelitian ini adalah orang tua dari balita yang terkena malaria yang datang berobat ke Puskesmas Sentani sebanyak 265 orang.

Sampel adalah sebagian dari keseluruhan objek yang diteliti dan dianggap mewakili seluruh populasi. Dengan kata lain sampel adalah elemen-elemen populasi yang dipilih berdasarkan kemampuan mewakilinya (Setiadi, 2013). Menurut Riyanto (2011) sampel merupakan sebagian dari populasi yang diharapkan bisa mewakili/representatif populasi. Sampel dalam penelitian ini adalah orang tua dari balita yang terkena penyakit malaria yang berobat di Puskesmas Sentani. Penentuan sampel yang digunakan yaitu purvosive sampling dengan rumus Slovin. 
Instrumen adalah alat yang digunakan oleh peneliti untuk mengumpulkan data (Dharma, 2011). Dalam penelitian ini menggunakan kuesioner. Adapun yang dimaksud dengan kuesioner adalah suatu teknik pengumpulan data dengan memberikan respons atas daftar pertanyaan tersebut (Noor, 2012). Kuesioner ini digunakan untuk memperoleh data mengenai karakteristik balita yang menderita penyakit malaria.

Dalam penelitian ini peneliti menggunakan skala Gutman. Skala Gutman digunakan bila ingin mendapatkan jawaban dengan tegas terhadap suatu permasalahan yang ditanyakan, misalnya jawaban ya dan tidak, benar dan salah, yakin dan tidak yakin dan sebagainya dimana skor tertinggi bernilai (1) dan skor terendah bernilai (0) (Sujarweni, 2014).

\section{HASIL DAN PEMBAHASAN}

\section{Karakteristik Umur Balita}

Umur atau usia adalah satuan waktu yang mengukur waktu keberadaan suatu benda atau makhluk, baik yang hidup maupun yang mati. Umur manusia dikatakan lima belas tahun diukur sejak dia lahir hingga waktu umur itu dihitung. Dengan demikian, umur itu diukur dari tanggal dia lahir hingga tanggal saat ini. Ada juga usia yang diukur dari tanggal kejadian itu bermula hingga tanggal saat ini. (Depkes RI 2008). Hasil penelitian dari 59 balita dengan malaria menunjukkan bahwa umur balita yang paling banyak adalah umur 2 tahun berjumlah 17 orang $(28,8 \%)$, kemudian 1 tahun berjumlah 16 orang $(27,1 \%)$, kemudian 3 tahun berjumlah 14 orang $(23,7 \%)$ dan yang paling sedikit adalah umur 4 tahun berjumlah 12 orang $(20,3 \%)$. Dibandingkan orang dewasa, anakanak memang lebih rentan terhadap penyakit karena sistem imunnya belum terbentuk dengan sempurna. Adapun usia anak paling rentan yaitu balita pada umumnya dan kurang dari satu tahun pada khususnya (Triasmara, 2013). Pendapat ini bertentangan dengan hasil penelitian ini karena anak/ balita yang paling banyak adalah yang berumur 2 tahun. 


\section{Karakteristik Jenis kelamin}

Menurut Hungu (2007), jenis kelamin adalah perbedaan antara perempuan dengan laki-laki secara biologis sejak seseorang lahir. Jenis kelamin berkaitan dengan tubuh lakilaki dan perempuan, perbedaan biologis dan fungsi biologis laki-laki dan perempuan tidak dapat dipertukarkan diantara keduanya, dan fungsinya tetap dengan laki-laki dan perempuan pada segala ras yang ada di muka bumi. Hasil penelitian berdasarkan jenis kelamin didapatkan bahwa balita dengan malaria yang paling banyak adalah laki-laki berjumlah 31 orang (52,5 $\%$ ) dan perempuan sebanyak 28 orang $(47,5 \%)$. Hal ini disebabkan karena daya tahan tubuh perempuan lebih kuat daripada laki-laki. Sesuai dengan penelitian Dr Maya Saleh di Institusi Penelitian Universitas Pusat Kesehatan McGill, didapatkan hasil bahwa perempuan punya sistem kekebalan tubuh yang lebih tinggi daripada laki-laki (Sjarief, 2016).

Penelitian yang dilakukan di Kabupaten Kupang, didapatkan hasil laki-laki: $122 \quad(65,7 \%) \quad$ dan perempuan: $63(34,3 \%)$ (Ngambut dan Sila, 2013). Penelitian di Kabupaten Melawi Kalimantan Barat, didapatkan hasil laki-laki: $60,3 \%$ dan perempuan $39,7 \%$ (Ristadeli, 2013). Penelitian tersebut sejalan dengan hasil penelitian ini karena jenis kelamin laki-laki lebih banyak terkena malaria daripada laki-laki.

\section{Jenis Malaria}

Menurut Harijanto (2011), terdapat 4 jenis malaria di Indonesia berdasarkan plasmodium yang menginfeksi yaitu: Tertiana, Tropika, Quartana dan Ovale. Penderita malaria dapat juga dihinggapi lebih dari satu jenis plasmodium atau biasa disebut mixed infection.

Berdasarkan jenis malaria pada balita didapatkan hasil bahwa jenis malaria terbanyak pada balita adalah Tropika sebanyak 44 orang $(74,6 \%)$, kemudian Tertiana sebanyak 14 orang $(23,7 \%)$, dan yang paling sedikit adalah Mix yaitu 1 orang (1,7 $\%)$. Hal ini sejalan dengan pendapat Sorontou (2013), bahwa kasus malaria yang paling banyak di Papua adalah falcifarum (tropika) dan vivax (Tertiana). 
Distribusi jenis malaria yang dilakukan oleh beberapa peneliti sebagai berikut: penelitian di kota Sawahlunto didapatkan hasil: tertiana $(76,92 \%)$, tropika $(15,38 \%)$ dan quartana (7,69\%) (Dwithania dkk, 2012). Penelitian di Kabupaten Pesisir Selatan didapatkan hasil: tropika $(91,67 \%)$ dan Tertiana (8,33\%) (Gusra dkk, 2013). Dari kedua penelitian tersebut, penelitian yang dilakukan oleh Gusra, dkk sejalan dengan hasil penelitian ini.

\section{Keluhan Awal}

Keluhan dan tanda klinis, merupakan petunjuk yang penting dalam diagnosa malaria. Gejala klinis ini dipengaruhi oleh jenis/strain Plasmodium, imunitas tubuh dan jumlah parasit yang menginfeksi. Waktu mulai terjadinya infeksi sampai timbulnya gejala klinis dikenal sebagai waktu inkubasi, sedangkan waktu antara terjadinya infeksi sampai ditemukannya parasit dalam darah disebut periode prepaten. Gejala pada anak biasanya disertai batuk (Harijanto 2011).

Pada penelitian ini didapatkan hasil keluhan awal yaitu menggigil sebanyak 44 orang $(74,6 \%)$, kulit teraba dingin sebanyak 41 orang $(69,5 \%)$, badan gemetar sebanyak 32 orang (54\%), terlihat pucat sebanyak 44 orang (74\%), mengalami mual sebanyak 37 orang $(62,7 \%)$, mengalami muntah sebanyak 40 orang $(67,8 \%)$, malas makan sebanyak 45 orang $(76,3 \%)$ dan malas minum sebanyak 37 orang $(62,7 \%)$. Adapun hasil skor keluhan awal yaitu terdapat keluhan awal dengan kriteria baik sebanyak 18 orang $(30,5 \%)$ dan kurang sebanyak 41 orang $(69.5 \%)$.

Menurut Harijanto (2011), gejala pada malaria tertiana adalah demam timbul setiap hari ketiga, masa tunas biasanya 12-17 hari, bahkan sampai 9 bulan, umumnya ditandai dengan gejala nyeri kepala, mual, muntah, serta badan lesu. Mula-mula demam tidak teratur, demam mulai teratur setiap 48 jam sekali, demam timbul sewaktu siang atau sore hari, suhu badan dapat mencapai $41^{\circ} \mathrm{C}$ yang merupakan demam pada malaria. Pada saat palpasi limpa terasa lembek (pada minggu kedua masa sakit), keadaan klien sampai memburuk, pusing serta 
mengantuk karena ada gangguan pada otak. Adapun gejala pada malaria tropika yaitu sakit kepala, pegalinu, lengan dan tungkai dingin, serta nyeri pinggang, timbul mual dan muntah, dan mungkin juga diare. Demamnya ringan juga tidak begitu nyata dan penderita tidak tampak sakit, jika penyakit ini tidak diobati maka umumnya berlangsung terus menerus dan gejala muncul semakin hebat.

Dari hasil penelitian ini ada beberapa keluhan yang sejalan dengan teori menurut Harijanto (2011) namun adapula keluhan atau gejala yang tidak dapat diketahui mengingat yang diteliti adalah balita.

\section{Lingkungan Tempat Tinggal}

Penyakit malaria bisa dialami oleh siapa saja, dan yang paling beresiko jika seseorang yang tinggal dan hidup di lingkungan yang banyak terdapat nyamuk. Nyamuk banyak ditemui dibagian lingkungan yang banyak penduduknya seperti perkotaan, terdapat genangan air, lingkungan yang masih rimbun dengan pepohonan, di daerah hutan atau perkebunan merupakan tempat yang banyak ditinggali nyamuk.
Kondisi lingkungan yang kotorpun banyak terdapat nyamuk dan juga terdapat banyak parasit sehingga akan menyebabkan malaria. (Dahlia, 2013). Pada penelitian ini berdasarkan lingkungan tempat tinggal responden didapatkan hasil sebagai berikut terdapat genangan air di sekitar rumah responden sebanyak 35 responden $(59,3 \%)$, parit/ selokan mengalami penyumbatan sebanyak 24 responden $(40,7 \%)$, terdapat rawa-rawa di sekitar rumah sebanyak 14 responden $(23,7 \%)$, terdapat semak-semak di sekitar rumah sebanyak 29 responden (49,2 \%), terdapat banyak pohon di sekitar rumah sebanyak 47 responden $(79,7$ $\%)$ dan menggunakan kelambu saat tidur malam 29 responden (49,2\%). Beberapa hasil penelitian mengenai lingkungan tempat tinggal yang menjadi faktor penyebab malaria yaitu: tidak memasang kawat kasa pada semua ventilasi, keberadaan genangan air dekat rumah, kebiasaan tidak memakai kelambu saat tidur pada malam hari, (Kurniawan, 2008). Dinding rumah yang terbuat dari kayu/papan (Babba, 2007). Keberadaan kolam, keberadaan 
semak di sekitar rumah, keberadaan genangan di sekitar rumah, (Ristadeli dkk, 2013). Keberadaan genangan air, keberadaan semak-semak, jenis dinding rumah dan tidak menggunakan obat anti nyamuk (Wahyuningtyas, 2011).

Penelitian tersebut sejalan dengan hasil penelitian ini tentang lingkungan tempat tinggal yang dapat menjadi tempat nyamuk bekembang biak. Apabila di sekitar rumah terdapat genangan air, parit/ selokan tersumbat, terdapat rawarawa, terdapat semak-semak dan banyak pohon maka hal-hal tersebut dapat memudahkan nyamuk bersarang dan berkembak biak di tempat tersebut sehingga kemungkinan orang di sekitarnya akan lebih mudah tergigit nyamuk terutama nyamuk malaria. Begitu pula dengan kebiasaan tidak menggunakan kelambu saat tidur dimalam hari maka beresiko tinggi terkena gigitan nyamuk.

\section{KESIMPULAN DAN SARAN}

Kesimpulan

$$
\begin{array}{rrr}
\text { Berdasarkan hasil dan } \\
\text { pembahasan yang dilakukan pada }
\end{array}
$$

bab V maka dapat ditarik kesimpulan sebagai berikut:

1. Sebagian besar umur balita yang terkena malaria adalah yang berumur 2 tahun.

2. Sebagian besar jenis kelamin balita yang terkena malaria adalah laki-laki akan tetapi perbandingan antara laki-laki dan perempuan tidak terlalu signifikan.

3. Sebagian besar jenis malaria pada balita adalah Tropika.

4. Sebagian besar keluhan awal balita adalah berat.

5. Sebagian besar lingkungan tempat tinggal responden adalah tidak beresiko malaria.

\section{SARAN}

1. Bagi Puskesmas Sentani Petugas kesehatan dapat memberikan penyuluhan tentang penyakit malaria kepada setiap pasien yang datang berobat ke Puskesmas Sentani agar masyarakat dapat memahami dengan baik tentang penyakit malaria sehingga kejadian malaria dapat mengalami penurunan. 
2. Bagi Stikes Jayapura

Hasil penelitian ini dapat mengembangkan dan meningkatkan bahan pembelajaran untuk memperkaya ilmu pengetahuan.

3. Bagi Penelitian Selanjutnya Peneliti selanjutnya dapat meneliti variabel lain dan metode lain untuk menjawab kebutuhan masyarakat dalam aspek kesehatan khususnya penyakit malaria.

4. Bagi masyarakat Masyarakat dapat menjaga lingkungan tempat tinggalnya agar tidak mudah terkena penyakit malaria dan apabila ada anggota keluarga yang mengalami gejala yang mengindikasikan penyakit malaria agar segera dibawa ke tempat pelayanan kesehatan terdekat.

\section{DAFTAR PUSTAKA}

Alwi, H. (2011). Kamus Besar Bahasa Indonesia. Jakarta: Gramedia Pustaka Utama.

Atikoh, I. N. (2014). Faktor-Faktor Yang Berhubungan Dengan Kejadian Malaria Di Desa
Selakambang

Kecamatan

Kalibondang

Kabupaten

Purbalingga.

Arikunto, S. (2010). Prosedur Penelitian: Suatu Pendekatan Praktik. Edisi Revisi. Jakarta: Rineka Citra.

Arsin, A. (2012). Malaria Di Indonesia (Tinjauan Aspek Epidemiologi). Makassar: Masagena Press.

Arsin, A. (2013). Hubungan Penggunaan Kelambu Berinsektisida Dengan Kejadian Malaria Di Kabupaten Halmahera Timur. Jurnal Masyarakat Epidemiologi Indonesia. Volume 1, No 3, Januari-Juni 2013.

Azwar, S. (2011). Metodologi Penelitian. Jakarta: Pustaka Belajar.

Babba, I. (2007). Faktor-Faktor Resiko Yang Mempengaruhi Kejadian Malaria. Semarang: Universitas Diponegoro.

Budiarto, E. (2002). Biostatistika Untuk Kedokteran Dan Kesehatan Masyarakat. Jakarta: EGC. 
Dahlia. (2013). Malaria Dan

Pengobatannya. Dikutip di http://www.manfaatnyasehat.co $\mathrm{m} /$ malaria-dan-pengobatannya/ Diakses tanggal 2 Mei 2016.

Depkes RI. (2008). Profil Kesehatan Indonesia. Jakarta.

Depkes RI. (2012). Profil Kesehatan Indonesia 2011. Jakarta: Kementrian Kesehatan Republik Indonesia.

Dharma, K. K. (2011). Metodologi Penelitian Keperawatan (Panduan Melaksanakan dan Menerapkan Hasil Penelitian). Jakarta: TIM.

Dwithania, M. Dkk. (2012). Insiden Malaria Di Puskesmas Sungai Durian Dan Puskesmas Talawi Kota Sawahlunto. Padang: FK Universitas Andalas.

Gusra, T. Dkk. (2013). Gambaran Penyakit Malaria Di Puskesmas Tarusan Dan Puskesmas Balai Selasa Kabupaten Pesisir Selatan Periode Januari- Maret 2013. Padang: FK Universitas Andalas.

Harijanto, P. N. (2011). Tatalaksana Malaria Untuk Indonesia.
Jakarta: Buletin Kementrian Kesehatan RI.

Hastono, S. (2007). Analisa Data Kesehatan. Jakarta: Universitas Indonesia.

Hidayat, A. A. A. (2007). Metode Penelitian Keperawatan Dan Tekhnik Analisa Data. Jakarta: Salemba Medika.

Hungu. (2007). Demografi Kesehatan Indonesia. Jakarta: Grasindo

Kemenkes RI. (2012). Pedoman Penatalaksanaan Kasus Malaria Di Indonesia. Jakarta.

Kemenkes RI. (2013). Riset Kesehatan Dasar (Riskesdas 2013).

Kurniawan, J. (2008). Analisis Faktor Risiko Lingkungan Dan Perilaku Penduduk Terhadap Kejadian Malaria Di Kabupaten Asmat. Semarang: Universitas Diponegoro.

Liwan, A. S. (2015). Diagnosis Dan Penatalaksanaan Malaria Tanpa Komplikasi Pada Anak. CDK-229. Vol. 40: No. 6. Bintuni. 
Mitayani., dan Sartika, W. (2010).

Buku Saku Ilmu Gizi. Jakarta:

Trans Info Media.

Nanda. (2013). Diagnosa

Keperawatan: Defenisi \&

Klasifikasi. Jakarta: EGC.

Ngambut, K., Dan Sila O. (2013).

Faktor Lingkungan Dan

Perilaku Masyarakat Tentang

Malaria Di Kecamatan Kupang

Timur. Kupang: Poltekkes

Kemenkes Kupang.

Noor, J. (2012). Metodologi

Penelitian: Skripsi, Tesis,

Disertasi \& Karya Ilmiah.

Jakarta: Kencana.

Nugroho, A. (2012). Malaria Dari

Molekuler ke Klinis:

Patogenesis Malaria Berat.

Jakarta: EGC.

Riyanto, A. (2011) Aplikasi

Metodologi Penelitian

Kesehatan. Yogyakarta: Nuha

Medika.

Ristadeli, T., dkk. (2013). Beberapa

Faktor Risiko Lingkungan Yang

Berhubungan Dengan Kejadian

Malaria Di Kecamatan Nanga

Ella Hilir Kabupaten Melawi.

Kalimantan Barat: Jurnal
Kesehatan Lingkungan

Indonesia.

Trenilmu. (2015). Pengertian Karakteristik Secara Umum.

Dikutip di http://www.trenilmu.com/2015/0 6/pengertian-karakteristiksecara-umum.html?. Diakses tanggal 2 Mei 2016.

Setiadi. (2013). Konsep Dan Praktik Penulisan Riset Keperawatan. Yogyakarta: Graha Ilmu.

Sjarief, M. (2016) Perempuan Lebih Kuat Daripada Laki-laki http//www.idntimes.com/terbukt i-berdasarkan-penelitianperempuan-lebih-kuat-daripadalaki-laki(23 Agustus 2016).

Soedarto. (2011). Malaria. Jakarta: Sagung Seto.

Soetjiningsih. (2012). Tumbuh Kembang Anak. Jakarta: EGC.

Solikhah. (2013). Identifikasi Vektor Malaria. Yogyakarta: FKM Universitas Ahmad Dahlan.

Sorontou, Y. (2013). Ilmu Malaria Klinik. Jakarta: EGC.

Sugiyono. (2011). Metode Penelitian

Kuantitatif, Kualitatif, Dan $R \& D$. Bandung: Alfabeta. 
Sujarweni, V. W. (2014). Panduan Penelitian Keperawatan Dengan SPSS. Yogyakarta: Pustaka Baru Press.

Sumantri, A. (2011). Metodologi Penelitian Kesehatan. Jakarta: Kencana.

Sutomo, B. \& Angraeni D. Y. (2010). Makanan Sehat Pendamping ASI. Jakarta: Demedia.

Triasmara. (2013) Cara Agar Balita Tidak Mudah Sakit. Dikutip di http://www.kompasiana.com/dr_ wahyutriasmara/12-cara-agarbalita-tidak-mudahsakit_5528aac8f17e612a718b45 c0. Diakses tanggal 23 Agustus 2016.

Wahyuningtyas, M. (2011). Hubungan Faktor Lingkungan Dan Perilaku Dengan Kejadian Malaria di Wilayah Kerja Puskesmas Ayah. Kebumen Wijaya, dkk. (2011). Pemeriksaan Mikroskopis Dan Tes Diagnostik Cepat Dalam Menegakkan Diagnosis Malaria. Denpasar: Fakultas Kedoteran Universitas Udayana

WHO. (2016). Malaria. Dikutip di http://www.who.int/mediacentre /factsheets/fs094/en/\#. Diakses tanggal 2 Mei 2016. 